\title{
O DIREITO DO CONSUMIDOR COMO FATOR DE PROTEÇÃO SOCIAL NA ATUAL SOCIEDADE DE CONSUMO
}

\author{
CONSUMER LAW AS PROTECTIVE FACTOR IN SOCIAL CURRENT \\ CONSUMER SOCIETY
}

\author{
${ }^{1}$ Daniela Ferreira Dias Batista
}

\begin{abstract}
RESUMO
O presente artigo tem como objetivo favorecer reflexões sobre a proteção social do consumidor através da aplicação e efetivação das normas consumeristas, destacando a vulnerabilidade do consumidor na atual sociedade de consumo em que vivemos, onde as pessoas são rotuladas de acordo com os produtos que adquirem ou os serviços que utilizam. Na sociedade de consumo a aquisição e utilização de determinados produtos e certos serviços se tornou sinônimo de bem-estar pessoal e reconhecimento de status social. A inversão de valores trazida pela coisificação das pessoas, revela claramente a vulnerabilidade do consumidor que ao sair dos padrões de moda ou de tecnologia, por exemplo, impostos pelo consumo, são considerados seres sociais improdutivos e consequentemente desnecessários a convivência em sociedade, o que acaba invariavelmente levando a sua exclusão. Nesse contexto social surge o consumo inconsciente e desequilibrado, onde o consumidor, na ânsia de se sentir produtivo e incluído socialmente, adquiri e utiliza mais produtos e mais serviços do realmente necessita, sem se atentar a sua realidade econômica. Assim, se torna evidente a importância da aplicação e do reconhecimento do Código de Defesa do Consumidor como norma de ordem pública e interesse social, que busca garantir a distribuição e o acesso igualitário aos bens de consumo, principalmente daqueles considerados essenciais, evitando graves problemas sociais como o superendividamento das famílias brasileiras, o que, nesse contexto, consequentemente, leva à improdutividade e à marginalização social.
\end{abstract}

Palavras-chave: Sociedade de consumo, Vulnerabilidade, Dignidade da pessoa humana, Proteção social

\footnotetext{
${ }^{1}$ Mestre em Direito pelo Centro Universitário Euripedes de Marília - UNIVEM, São Paulo (Brasil) Professor de Direito pelo Centro Universitário Euripedes de Marília - UNIVEM, São Paulo (Brasil) E-mail: danieladbatista@gmail.com
} 


\begin{abstract}
This article aims to foster reflection on the social protection of consumers through the application and effectiveness of consumeristas standards, highlighting consumers' vulnerability in the current consumer society we live in, where people are labeled according to the products they purchase or the services they use. In consumer society the acquisition and use of certain products and certain services has become synonymous with personal wellbeing and recognition of social status. The inversion of values \&\#8203;\&\#8203;brought about by the "objectification" of the people, clearly reveals consumer vulnerability that coming out of fashion or technology standards, for example, the consumption taxes are considered unproductive social beings and therefore unnecessary coexistence in society, which invariably ends up leading to their exclusion. In this social context arises the unconscious and unbalanced consumption, where consumers, eager to feel productive and socially included, purchase and use more products and more services really need, with little regard to their economic reality. Thus, it becomes evident the importance of the implementation and recognition of the Consumer Protection Code as the standard of public order and social interest, which seeks to ensure the distribution and equal access to consumer goods, especially those considered essential to avoid serious social problems as the indebtedness of Brazilian households, which, in this context, therefore, leads to unproductive and social marginalization.
\end{abstract}

Keywords: Consumer society, Vulnerability, Dignity of the human person, Social protection 


\section{INTRODUÇÃO}

O presente artigo foi elaborado com o objetivo de favorecer reflexões sobre a possibilidade de proteção social do consumidor vulnerável, através da efetivação das normas de consumo, destacando os efeitos socioeconômicos da sociedade de consumo ou de consumidores, a caraterística vulnerável do consumidor frente a sociedade atual e a necessidade da proteção desse consumidor, bem como, da garantia jurídica do acesso aos produtos e serviços considerados essenciais a existência digna de todo e qualquer ser humano.

$\mathrm{Na}$ realidade social em que vivemos o consumo de produtos e serviços representa a inclusão social, pois a condição de consumidor ativo no mercado traz a cada pessoa a realização máxima de sua liberdade e dignidade, podendo usufruir dos benefícios do mercado globalizado, satisfazendo suas necessidades e seus desejos.

Nos dias atuais são evidentes os efeitos que o consumo de produtos e serviços provocam no indivíduo e no meio social em que este convive. A sociedade, de forma geral, rotula as pessoas de acordo com os bens que consomem, incluindo-as ou excluindo-as de sua convivência, e, muitas vezes, esse "rótulo" não condiz com a verdadeira realidade econômica e social do indivíduo.

$\mathrm{Na}$ sociedade capitalista e globalizada, o consumo se tornou uma "máxima" de existência digna do ser humano, de ascensão social e econômica, ou seja, sendo ativo no mercado de consumo, a pessoa existe como cidadão que produz economicamente e que possui bens a serem respeitados. O problema é que na maioria das vezes não se tratam de produtos ou serviços essenciais, como alimentos, água e energia elétrica.

O que realmente preocupa é o consumo exacerbado de itens muitas vezes desnecessários e supérfluos, como por exemplo os últimos lançamentos de acessórios de moda ou da tecnologia, que se tornaram ilusoriamente essenciais para se atingir a um determinado status social ou até uma condição de incluído, de aceito socialmente. Ou seja, certo ou errado, temos que lidar com a atual realidade, em que o consumo é visto pela sociedade como um adjetivo líquido e certo de riqueza, de inteligência, de beleza, de força, de popularidade ou de todos os seus antônimos.

A sociedade de consumidores é um tipo de sociedade que interfere diretamente nas atitudes de seus membros, dirige-se a eles, os saúda, apela a eles, questiona-os, mas também os interrompe e "irrompe sobre" eles. Essa sociedade avalia seus membros, recompensando ou penalizando, pois espera ser entendida, seguida e obedecida por eles. Como resultado, os membros são alocados de acordo com seu desempenho consumista, sendo este o principal fator 
de estratificação e o maior critério de inclusão e exclusão da sociedade, assim como orientam a distribuição do apreço e doa estigmas sociais. (BAUMAN, 2088, p. 70-71).

Sendo assim, na sociedade de consumo ou de consumidores é pública e notória a inversão de valores, na qual é o produto ou o serviço que dita a existência social de uma pessoa; é o celular mais moderno, a roupa da moda ou de uma determinada grife famosa, o último modelo de carro ou o que custa mais caro, que vai determinar a inclusão e o reconhecimento do indivíduo na sociedade. Dessa forma, sua existência social e por consequência digna, acaba sendo atrelada aos seus bens de consumo e não ao seu valor moral, como pessoa, indivíduo que na verdade deveria ser reconhecido por suas atitudes como cidadão.

A realidade da exclusão ou inclusão social causada pelo consumismo fica muito bem ilustrada na frase da artista norte-americana, Barbara Krugman, citada em um comentário de economia do sociólogo Joelmir José Beting, que, ao resumir o estado de espírito presente nos tempos atuais, arrisca-se a transformar a famosa máxima da filosofia ocidental "Penso, logo existo", em "Consumo, logo existo". (BETING, 2012, online).

A sociedade atual e globalizada criou uma ideologia de que o consumo é sinônimo de felicidade, de bem-estar e de existência representativa na sociedade civilizada. A capacidade aquisitiva no mercado de consumo, é medida de valoração dos indivíduos no processo civilizatório e fonte de aferição do prestígio social das pessoas. A necessidade, real ou implantada, de adquirir e acumular bens de consumo deixa de ser um meio para a realização da vida social, tornando-se um fim em si mesmo, um símbolo para a inclusão e o reconhecimento social.

Com o Código de Defesa do Consumidor (CDC), Lei Federal 8.078, de 11 de setembro de 1990, surgiu no Brasil uma regulamentação expressa e específica da proteção e defesa do consumidor, que busca primordialmente atingir o equilíbrio nas relações de consumo, protegendo o consumidor vulnerável, para então alcançar a igualdade real das partes envolvidas, garantindo acesso aos produtos e serviços com qualidade e segurança, principalmente aqueles considerados essenciais, buscando por fim, evitar e combater as práticas abusivas para harmonizar os interesses na sociedade de consumo brasileira.

Cabe salientar que o próprio direito consumerista estabelece que o consumidor é considerado vulnerável de forma presumida e absoluta, não cabendo prova em contrário, pois sendo destinatário final do produto ou do serviço, se torna a parte mais fraca da relação jurídica de consumo, assumindo uma posição inferior ao fornecedor de forma técnica, jurídica ou socioeconômica. 
As normas consumeristas trazidas pelo referido estatuto legal são de ordem pública e interesse social (art. $1^{\circ}, \mathrm{CDC}$ ), caracterizando os direitos do consumidor como indisponíveis e fazendo com que todo ato ou negócio jurídico contrário às previsões do código, seja considerado nulo de pleno direito, o que demostra claramente a importância social que o legislador deu ao sistema legal consumerista.

A Constituição Federal prevê a defesa do consumidor como garantia e direito fundamental, consequentemente, os direitos previstos no Código de Defesa do Consumidor ou em qualquer outra fonte do direito que verse sobre o assunto, ganham status de direitos fundamentais, protegidos rigorosamente pela Carta Magna brasileira que, consequentemente, impõe sua aplicação de ofício para a devida efetivação dos direitos consumeristas.

A preocupação do constituinte com os direitos do consumidor foi deveras retumbante, o que se revelou pelo significativo destaque que a matéria mereceu, tendo sido, inclusive, situada entre os direitos e as garantias fundamentais indisponíveis, previstos expressamente no artigo $5^{\circ}$, XXXII, da Constituição Federal Brasileira. Isto é, a proteção do consumidor é elencada constitucionalmente junto com os direitos mais importantes tutelados na hierarquia constitucional, como por exemplo, o direito à propriedade e à igualdade.

O direito do consumidor é de suma importância por combater os desequilíbrios nas relações de consumo para aquisição dos produtos e serviços considerados essenciais à condição de existência digna do ser humano, regulamentando principalmente a qualidade, as informações e a eficiência dos bens disponibilizados ao cidadão no mercado, como é o caso, por exemplo, dos alimentos, que são produtos vinculados diretamente à saúde do consumidor, à desnutrição e às doenças que podem ser causadas ou agravadas pela ingestão de produtos de má qualidade, sem a devida conservação ou ainda, de produtos com informações incorretas ou imprecisas.

Sendo assim, não pode o direito do consumidor ser considerado secundário na ciência jurídica, pois este ramo do Direito lida diretamente com o essencial da vida humana, visando garantir os princípios da dignidade humana e o mínimo existencial, este entendido como "o conjunto de garantias materiais para uma vida condigna”. (SARLET, 2007, p. 103).

O consumo de produtos e serviços está diretamente relacionado à dignidade da pessoa humana, à sua existência e sobrevivência digna, pois não há como conceber a ideia de existência digna de um ser humano sem que tenha acesso a produtos e serviços essenciais de qualidade e com segurança, como por exemplo, o tratamento de esgoto e o fornecimento de água e energia elétrica, bem como a alimentação. Por isso, é latente a necessidade da efetivação das normas de 
consumo, buscando a conscientização da sociedade e o equilíbrio nesta relação jurídica, para garantia do princípio da dignidade da pessoa humana.

A efetivação das normas de consumo é essencial a proteção do consumidor, ser vulnerável na sociedade de consumo, onde consumir é sinônimo de inclusão social, ou seja, o Código de Defesa do Consumidor deve ser observado, cumprido e respeitado para que exista um real equilíbrio na relação jurídica de consumo e para que o consumidor consiga efetuar seu papel na sociedade de forma equilibrada e consciente, para que assim, sua existência social se perpetue.

\section{A SOCIEDADE DE CONSUMO E SEUS REFLEXOS}

Quando falamos em Direito do Consumidor ou no próprio Código de Defesa do Consumidor não temos a real concepção do "poder" de proteção social que as leis consumeristas podem oferecer, pois num primeiro momento a ideia de consumo nos leva a pensar erroneamente em algo supérfluo ou facultativo, onde as pessoas podem agir de acordo com sua própria vontade ou necessidade, diferentemente de um direito fundamental ou social.

Porém, quando revelamos os aspectos, as características da atual sociedade de consumo, percebemos que a relação jurídica de consumo vai muito além da concepção legal, positivista de direitos e deveres em um simples contrato de compra e venda ou de prestação de serviço, na realidade a relação de consumo vai refletir diretamente nos valores humanos, nos valores morais de uma população.

O consumo atualmente deve ser visto com outros "olhos", com cuidados especiais, buscando um equilíbrio social, pois hoje somos reféns de uma sociedade onde o consumo, certo ou errado, é tão valioso quanto os valores de liberdade ou de igualdade. Frases populares usadas frequentemente em conversas descompromissadas ou postadas em redes sociais como: "dinheiro não é tudo, mas é 100\%", "dinheiro não traz felicidade, mas compra tudo que me leva a ela", revelam a verdadeira preocupação da sociedade em consumir, que para disfarçar o "politicamente incorreto", faz trocadilhos com as palavras criando piadas.

A suma importância que as normas de consumo representam para a conquista de um equilíbrio socioeconômico, se torna evidente quando refletimos sobre essa sociedade de consumo em que vivemos atualmente e os reflexos causados na vida de cada um de seus indivíduos que podem ser incluídos ou excluídos de acordo com sua atuação no mercado de consumo. 
Como exclusão social é um termo que demanda forte debate acadêmico e doutrinário, principalmente em relação aos conceitos de igualdade e desigualdade, para fins didáticos o conceito de exclusão utilizado no presente trabalho terá como alicerce os ensinamentos do sociólogo francês Robert Castel, que retrata a exclusão social como:

\begin{abstract}
A presença, aparentemente cada vez insistente, de indivíduos colocados em situação de flutuação na estrutura social e que povoam seus interstícios sem encontrar aí um lugar designado. Silhuetas incertas, à margem do trabalho e das fronteiras das formas de troca socialmente consagradas - desempregados por período longo, moradores dos subúrbios pobres, beneficiários da renda mínima de inserção, vítimas das readaptações industriais, jovens à procura de emprego e que passam de estágio a estágio, de pequeno trabalho à ocupação provisória... - quem são eles, de onde vêm, como chegaram ao ponto em que estão, o que vão se tronar? (CASTEL, p. 23, 1998).
\end{abstract}

Nesse sentido podemos entender a exclusão social como um processo de marginalização, de falta de interatividade com o restante da sociedade, onde o excluído não está dentro da normalidade entendida e aceita pela maioria dos entes sociais, assim não está adequado ao convívio social e por isso acaba sendo rejeitado pela sociedade.

O que podemos perceber, nas publicidades, nas redes sociais, nos diversos meios de comunicação e nas relações humanas em geral é que cada dia mais o consumo é sinônimo de existência social, ou seja, o que a pessoa tem, o que ela efetivamente possui, é o que importa e não suas características pessoais, seus valores morais ou seu comportamento social. A ideia é de que o "ter" esteja acima do "ser", sendo que os excluídos da sociedade são aqueles que não consomem o produto ou o serviço mais popular, mais moderno, mais caro, mais bonito, ou simplesmente não consome.

De acordo com a professora e psiquiatra Ana Beatriz Barbosa Silva:

Enquanto a sociedade alicerçada no ser prioriza as pessoas, a embasada no ter tem como prioridade coisas que podem ser compradas por valores determinados pelo mercado. Infelizmente, a sociedade em que vivemos tem como senso comum vigente o modo ter de estabelecer suas regras e seus valores. Por essa razão, podemos denominá-la de sociedade consumista ou sociedade de produtos. Nesse contexto social, é necessário possuir tudo que seja capaz de gerar prazer de forma intensa e imediata. Outra característica que pode tornar um produto bem mais valorizado no mercado é seu grau de exclusividade. Quanto menos compartilhado é o grau de exclusividade. Quanto menos compartilhado for um objeto (e/ou experiência), mais valor ele terá e mais status dará a pessoa a quem o possuir. (SILVA, p. 18-19, 2014).

A sociedade de consumo impõe aos seus indivíduos um modo de vida onde não consumir é muito mais que não ser reconhecido socialmente, é simplesmente não existir em sociedade. Por isso a sociedade de consumidores se revela liquida, ou seja, economicamente valorável e possivelmente vendável, onde se pode comprar e vender tudo, desde os bens 
materiais até os bens imateriais, como a moral, o caráter e porque não a inclusão do indivíduo em sociedade, na sociedade liquida as pessoas se tornam as próprias mercadorias.

O filósofo francês Gilles Lipovetsky caracteriza empiricamente a sociedade de consumo por diferentes traços:

Elevação do nível de vida, abundância das mercadorias e dos serviços, culto dos objetos e dos lazeres, moral hedonista e materialista etc. Mas, estruturalmente, é a generalização do processo de moda que a define propriamente. A sociedade centrada na expansão das necessidades é, antes de tudo, aquela que reordena a produção e o consumo de massa sob a lei da obsolescência, da sedução e da diversificação, aquela que faz passar o econômico para a órbita da forma moda. (LIPOVETSKY, p. 184, 2009).

Nesse sentido temos que a atual sociedade de consumo é aquela que não se importa com as necessidades reais para uma existência digna e sim com a adequação à "moda", ou seja, o que importa é atender aquilo que é imposto pela mídia em geral, pelo mercado de consumo e até pela própria sociedade consumista, como sendo o correto, o melhor, o necessário, assim e somente desta maneira o indivíduo é reconhecido como ser existente em sociedade, as necessidades individuais, os valores subjetivos de cada um deixam de ser o necessário, passando a importar somente o que é dito e porque não imposto pela "moda".

Baseado no entendimento de Lipovetsky (2009), podemos dizer que a moda é uma das engrenagens que constituem a sociedade contemporânea, mesmo sendo este fenômeno, erroneamente visto como um sinônimo para o glamour, o fetiche, a futilidade e a superficialidade. Ao contrário do que prega seu estereótipo geral, moda interfere constantemente na vida das pessoas, seja nos seus relacionamentos, nas suas atitudes, suas personalidades ou nos seus hábitos cotidianos, dessa forma sua função vai muito além desse pensamento predefinido de moda-fútil. A sociedade segue um círculo consumista e por existir várias "modas" possíveis acha que possui uma identidade própria, quando na verdade só está escolhendo dentro daquilo que lhe foi imposto.

Para o sociólogo polonês Zygmunt Bauman são representações típicas da fragmentação social que vivemos os aspectos como o desejo pela "fama" no sentido de reconhecimento pessoal, pela ascensão pública e o consumo excessivo de produtos e serviços considerados supérfluos, característicos da atual sociedade, onde obrigatoriamente é necessário se tornar notável, sendo que a propriedade ou a simples utilização de produtos ou serviços considerados ultrapassados, passa a ser vista como sinônimo de estupidez pelos demais indivíduos sociais (BAUMAN, p. 53, 2008).

A sociedade de consumidores é uma realidade atual, cada dia mais perceptível e ao mesmo tempo perigosa, pois propõe as pessoas o surgimento incessante de necessidades, com 
promessas de satisfação pessoal e social, com felicidade garantida a cada nova compra. Essa "promessa" do consumo de uma nova vida ao consumidor, de um reconhecimento e de um renascimento em sociedade, é exatamente o que levam as pessoas a depender de forma tão significativa do consumo de produtos e serviços.

O valor mais característico da sociedade de consumidores, na verdade seu valor supremo, em relação ao qual todos os outros são instados a justificar seu mérito, é uma vida feliz. A sociedade de consumidores talvez seja a única na história humana a prometer felicidade na vida terrena, aqui e agora e a cada "agora" sucessivo. Em suma, uma felicidade instantânea e perpetua. Também é a única sociedade que evita justificar e/ou legitimar qualquer espécie de infelicidade (exceto a dor infligida aos criminosos como "justa recompensa" por seus crimes), que recusa-se a tolerá-la e a apresenta como uma abominação que merece punição e compensação. (BAUMAN, p. 60, 2008).

É exatamente nesse ponto que a sociedade de consumo se torna "perigosa", a promessa de felicidade não é uma garantia individual a todos os consumidores, que mesmo comprando o que lhe é oferecido como "felicidade certa", nem sempre alcança o efeito prometido e esperado e, então, frustrado por não conseguir fazer parte dessa sociedade "feliz e perfeita", o consumidor consome mais e mais, de forma irracional e exacerbada, levado pelas pseudonecessidades que lhe foram criadas pela própria sociedade em que vive e da qual quer incansavelmente fazer parte.

A felicidade é algo muito particular, individual, que não pode ser "vendido" como certo e concretamente atingível para todo e qualquer consumidor de forma satisfatória, assim o filósofo Immanuel Kant, na Crítica da Razão Pura, definiu que "a felicidade consiste na satisfação de todas as nossas inclinações", portanto, algo puramente pessoal e incomunicável. Com efeito, ela pode ser concebida e manifesta de diversos modos, e a vontade do homem, em sua relação, não é possível de ser reduzida a um princípio comum válido para todos. Princípios empíricos são subjetivos e contingentes, logo, a posteriori, e relacionam-se com as mais variadas finalidades; e a satisfação baseada em princípios empíricos não é outra coisa senão a felicidade. (KANT, p. 179-180, 1996).

Segundo o sociólogo e filósofo francês Jean Baudrillard:

Todo o discurso sobre as necessidades assenta numa antropologia ingênua: a proteção da propensão natural para a felicidade. Inscrita em caracteres de fogo por detrás da menos publicidade para as Canárias ou para os sais de banho, a felicidade constitui a referência absoluta da sociedade de consumo, revelandose como o equivalente autentico da salvação. (BAUDRILLARD, p. 47, 2007).

Baudrillard ainda ressalta a importância da relação estabelecida entre o mito da felicidade prometida pela sociedade de consumo e o mito da igualdade, ou seja, para que a 
felicidade seja o veículo do mito igualitário, ela deve ser mensurável, representando o bemestar do consumidor por objetos e signos, devendo ser visível a todos, assim, a felicidade na sociedade de consumo deve ser provada, como exigência, no ideal de consumo, de igualdade ou distinção. A felicidade não representaria mais um estado interior, próprio de cada ser humano, sem necessidade de provas, ao contrário, ela deve ser ostentada para a sociedade através da posse e utilização dos bens de consumo. (BAUDRILLARD, p. 47-48, 2007).

O Mito da Igualdade conduz à degeneração dos valores e dos ideais. Honra, fidelidade e transcendência são virtudes aristocráticas (isto é, elas são virtudes de homens superiores), e, como tal, não têm lugar na sociedade dos "iguais". O resultado, não surpreendentemente, é a decadência social, lares e famílias destroçadas, crime, vícios, inveja, enfim, os frutos do igualitarismo. Mesmo a Arte é afetada pela mão maligna do igualitarismo, pois a sociedade igualitária direciona todas as suas energias na pacificação e divinização do "homem normal" (em termos matemáticos, o mais baixo denominador comum). O resultado é "arte" desprovida de sentido, destinada a chocar ou simplesmente a ornamentar. Tudo isto está travestido. (SMITH, online, 2008).

Assim, a felicidade prometida pela sociedade de consumo levaria a uma igualdade somente entre aqueles que consomem o que lhe "posto" e por quer não "imposto" a ser consumido, ou seja, quem não consome é desigual e como tal deve ser excluído da sociedade, o objeto do consumo é antes de tudo um signo, um símbolo que tem a função máxima de representação social, que configura o status de pessoa e que de alguma maneira está alheia da realidade.

Vivemos numa época em que quase tudo pode ser comprado e vendido. Nas três últimas décadas, os mercados - e os valores de mercado - passaram a governar nossa vida como nunca. Não chegamos a essa situação por escolha deliberada. É quase como se a coisa tivesse se abatido sobre nós. Veja-se a questão da desigualdade. Numa sociedade em que tudo está à venda, a vida fica mais difícil para os que dispõem de recursos modestos. Quanto mais dinheiro pode comprar, mais importante é a afluência (ou sua falta). (SANDEL, p. 11 e 14, 2012).

O pensamento do consumidor na sociedade em que vivemos é de que: se o consumo pode lhe fazer bem, então "devo consumir até ser feliz e, se eu não consumir não vou ser feliz e não serei incluído na sociedade da qual quero me pertencer".

Com esse pensamento o consumidor se torna cada vez mais vulnerável aos anseios da sociedade de consumo, as publicidades e as novidades ditadas pelos fornecedores como sendo o melhor para cada ser humano, assim, nunca foi tão evidente a necessidade de uma lei que proteja efetivamente os consumidores, que na busca incessante de fazer parte da "sociedade feliz", consome de forma inconsciente, compulsiva e descontrolada, gerando, além da própria 
insatisfação pessoal, um dos maiores problemas econômico-sociais dos dias atuais, o superendividamento do consumidor.

Nessa ânsia do consumidor de se sentir parte dessa sociedade de consumo, mesmo sem qualquer condição financeira, ele se sente envolvido em uma situação que não consegue sair, onde seu rendimento não é mais suficiente para honrar suas obrigações e garantir sua subsistência digna, caracterizando o superendividamento, o que acaba lhe excluindo ainda mais por ser mais produtivo para a sociedade de consumo.

De acordo com o Departamento de Proteção e Defesa do Consumidor do Ministério da Justiça brasileiro o superendividamento pode ser definido como impossibilidade global do devedor-pessoa física, consumidor, leigo e de boa-fé, de pagar todas as suas dívidas atuais e futuras de consumo (excluídas as dívidas com o Fisco, oriundas de delitos e de alimentos) em um tempo razoável com sua capacidade atual de rendas e patrimônio. (CADERNO de Investigações Científicas, 2012, on line).

O problema do endividamento demasiado é que mesmo com todas as dívidas as famílias não deixam de consumir, pois do contrário deixariam de existir ou, ao menos, seriam excluídas da sociedade a que, querendo ou não, pertencem, assim, a dívida aumenta, os débitos não são quitados e chegasse ao superendividamento, fenômeno que afeta diretamente o desenvolvimento socioeconômico do país, pois impõe limites ao crescimento da economia, consequentemente, desacelerando o mercado de trabalho, a prestação de serviço, como divulgou em setembro de 2014, o Instituto Brasileiro de Geografia e Estatística (IBGE), em julho deste ano, o setor de serviços tiveram o menor crescimento da série histórica iniciada em janeiro de 2012 (4,6\% em julho de 2014 ante julho de 2013).

Conforme demonstrado no Relatório de Estabilidade Financeira do Banco Central, divulgado em março de 2014, o endividamento das famílias brasileiras já compromete quase a metade do total de sua renda, as dívidas familiares consumiam $45,73 \%$ da renda acumulada em 12 meses, num processo que só cresce desde 2009.

Interessante ressaltarmos que para os fornecedores (comerciantes, fabricantes, produtores, importadores, profissionais liberais etc.) a compra compulsiva e descontrolada que na maioria das vezes, tem altos valores e grandes quantidades, até pode, num efeito mediato, parecer vantajosa, porém a ilusão se revela num futuro não muito distante, pois a compra conduzida por tais elementos, na maioria das vezes resulta em inadimplência do consumidor e, consequentemente prejuízo para o fornecedor, que se vê sem seu produto ou serviço e sem o devido pagamento. 
Na sociedade de consumo atual a aquisição de certos produtos e a utilização de alguns serviços na maioria das vezes é obrigatória, é imposta ao cidadão, pois não há como se viver propriamente dito ou conviver socialmente sem adquirir o mínimo de produtos alimentícios, sem comprar produtos de vestuário, sem utilizar serviços de transporte, fornecimento de energia elétrica, água, tratamento de esgoto, serviços relacionados à saúde, assim, podemos concluir de forma lógica que certos consumos são impostos, ficando o consumidor a mercê das "vontades" do mercado de consumo "fabricado" pelos fornecedores.

Essa "imposição" de consumo coloca o consumidor em uma posição de refém, produzindo uma demanda cada vez maior de proteção ao consumidor, principalmente pelo já salientado endividamento, um dos maiores problemas socioeconômicos oriundos do consumo desequilibrado.

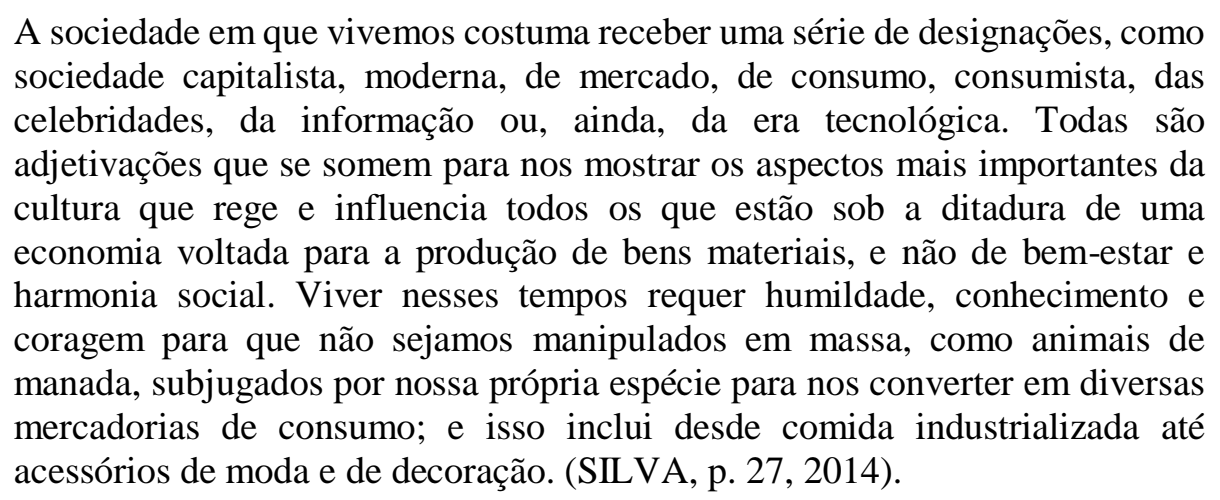

Um recente estudo realizado pelo SPC Brasil - sistema de informações das Câmaras de Dirigentes Lojistas, constituindo-se o mais completo banco de dados da América Latina em informações creditícias sobre pessoas físicas e pessoas jurídicas - constatou que os brasileiros inadimplentes ficam com o nome registrado como devedor nos órgãos de proteção ao crédito por aproximadamente dois anos, sem conseguir quitar suas dívidas, devendo para 3,7 diferentes empresas, comprometendo mais de sete vezes sua renda mensal com dívidas atrasadas. Em média o consumidor com uma renda familiar de $\mathrm{R} \$ 2.822,00$ (dois mil oitocentos e vinte e dois reais) possui o total de $\mathrm{R} \$ 21.676,00$ (vinte um mil seiscentos e setenta e seis reais) em dívidas junto às empresas credoras. (SPC, on line, 2015).

A referida pesquisa sobre a recuperação de crédito no Brasil constatou ainda que quase a metade dos consumidores entre inadimplentes e ex-inadimplentes (48\%) ouvidos afirmam que a falta de planejamento no orçamento pessoal é principal a razão apontada para não pagar as contas. Em seguida, entre as justificativas citadas, vem a perda do emprego (28\%), a diminuição da renda (21\%), o atraso de salário (17\%) e as compras acima do que lhes permitia o orçamento $(16 \%)$. 
Mesmo com todos os problemas da sociedade de consumo, sabemos e devemos aceitar como certo que consumir é preciso e deve ser uma atividade saudável que faz parte do cotidiano de todo ser humano, o que preocupa é que as pessoas dessa mesma sociedade, não estão preparados para viver um consumo consciente e equilibrado e, assim, confundem o consumo primário que satisfaz as suas necessidades essenciais ou reais, com o consumo secundário que é criado ou imaginado como necessário.

O consumo primário se verifica pelo consumo de bens essenciais, estando diretamente vinculado a subsistência, a sobrevivência do ser humano de forma digna, sendo responsável principalmente pela obtenção de comida, de abrigo físico, da proteção pessoal, da manutenção do lar, da higiene pessoal e da saúde. Já o consumo secundário é aquele vinculado a prazeres pessoais criados de forma subjetiva e individual por cada consumidor avido pela sensação de prazer, de satisfação e de se sentir parte de um todo significativo em sua existência social, são desejos socialmente valorizados e não necessidades reais.

$\mathrm{Na}$ atual sociedade de consumo seus integrantes são tomados por uma sensação desagradável de exclusão quando não compra coisas que são validadas pelo marketing como necessárias à felicidade, se sentindo excluídos e até mesmo fracassados e deprimidos, ou seja, em casos extremos, o que o indivíduo consome passa a ser sentido como uma demonstração da sua identidade e da sua capacidade frente a seu grupo social. "Algo ao estilo: 'Sou o que consumo, e o que consumo estampa aos outros o que sou'”. (SILVA, p. 43, 2014).

O grande desafio para o equilíbrio no consumo é lidar ou, por que não, controlar essa sensação de felicidade, de prazer e de inclusão quando compramos um produto ou utilização um serviço socialmente "aprovado". O fato é de que as pessoas compram algo buscando satisfação pessoal, que pode ser real no caso dos bens essências a manutenção de sua vida ou saúde, ou que pode ser uma falsa satisfação, ou melhor, uma satisfação transitória e desnecessária, no caso dos produtos e serviços considerados supérfluos, onde a necessidade de aquisição é criada através da publicidade feita pelos comerciantes e fabricantes e, pela própria manutenção de existência na sociedade de consumo.

Por isso é vital a existência jurídica das normas que regulam a relação jurídica de consumo e, consequente tão necessária se faz a efetivação delas. O consumidor é somente um número, um índice, um potencial, ou seja, é somente um objeto para a sociedade de consumo, onde os fornecedores lhe veem como meta a ser alcançada a qualquer custo no final de cada mês e os demais consumidores, integrantes dessa sociedade, lhe veem como o "dono" do automóvel zero quilômetros, do celular de última geração, da bolsa de grife, rotulando-o, de acordo com o valor daquilo que você possui ou utiliza. 
É nessa sociedade que a lei precisa proteger o ente consumidor, que desde sempre é vulnerável, pois acredita que consumindo será feliz, satisfeito e integrado em sua comunidade, mesmo que para consumir tenha que ficar à mercê dos mandos e desmandos do mercado de consumo, visto que ninguém consegue escolher o que realmente quer comprar ou utilizar, se não dentre aquelas opções que são disponibilizadas para nós previamente pelos fornecedores baseados em uma pseudo necessidade, ou melhor, em desejos de uma maioria que se considera consumidores socialmente ativos.

O Direito do Consumidor é, pois, a disciplina jurídica da "vida cotidiana" do habitante da sociedade de consumo. Seu surgimento, com alterações profundas no direito tradicional, decorre diretamente da revolução industrial (com produção, comercialização, consumo, crédito e comunicação em massa), já que esta mudou, por inteiro, o dia-a-dia dos homens - agora chamados consumidores. (BENJAMIM, p. 99, online).

O Código de Defesa do Consumidor estabelece em seu artigo $4^{\circ}$, I, como princípio da Política Nacional de proteção e defesa do consumidor o reconhecimento de sua vulnerabilidade de forma presumida e absoluta, não cabendo prova em contrário, pois nesse contexto da sociedade de consumo não há como aceitarmos a possibilidade de que alguém consiga viver bem e socialmente reconhecido sem ter que consumir, assim se torna um alvo fácil para as práticas comerciais do mercado de consumo que de certa forma impõe ao consumidor a aquisição de bens de acordo com a oferta de produção e não de acordo com a demanda realmente necessitada pela sociedade.

Não se pense, contudo, que a mera vulnerabilidade do consumidor conseguiria, per se, sensibilizar o legislador ou o aplicador. A "universabilidade" desta vulnerabilidade é que explica a intervenção legislativa. Quanto maior for o número de vulneráveis, maior será a sensibilidade estatal. É que em uma sociedade democrática, compreensível, a equação numérica tem enorme peso. Esta é a razão para que o Direito, muitas vezes, fique ao lado da maioria mesmo que com a minoria esteja o poder e a riqueza. Daí que o Direito do Consumidor não se justifica apenas como produto da sensibilidade do legislador para com a vulnerabilidade do consumidor. Igualmente relevante no seu desenvolvimento é o fato de que os consumidores são imensamente majoritários no mercado. (BENJAMIM, p.

99, online).

Sendo assim, a efetivação das normas de consumo se torna essencial a proteção desse consumidor vulnerável resultado da sociedade de consumo em que vivemos, onde comprar é sinônimo de existir socialmente, é referência de status econômico e de reconhecimento perante os demais membros da sociedade, com o cumprimento das regras jurídicas, como por exemplo 
a conscientização e a educação para o consumo, o cidadão consumidor estaria preparado para se comportar corretamente perante aos anseios do mercado de consumo, adquirindo produtos e utilizando serviços de acordo com suas reais necessidades e conforme sua vontade e possibilidade econômica, sem ser ludibriado pelas falsas promessas de "felicidade" e inclusão social.

Por todo o exposto resta-se evidente a importância do direito do consumidor na atual sociedade, sobretudo diante da sua expressão maior como direito fundamental, cuja dimensão vai encontrar ideal suporte no necessário equilíbrio do mercado de consumo, nos valores sociais da livre iniciativa econômica e na razão de ser do Direito voltada a preservar a igualdade e a dignidade da pessoa humana e efetivar a justiça social.

\section{CONSIDERAÇÃO FINAIS}

O presente artigo demonstra como a importância da devida aplicação e efetivação das normas jurídicas regulamentadoras da relação de consumo, é essencial e claramente necessária para a proteção social do consumidor vulnerável, principalmente na sociedade consumista em que vivemos atualmente.

Quando falamos em exclusão social a primeira necessidade latente que surge na tentativa de abolir tal fenômeno é exatamente a proteção do vulnerável, do marginalizado, a efetivação mais abrangente possível da igualdade social para a concretização da dignidade da pessoa humana que necessita viver em sociedade.

O Código de Defesa do Consumidor, lei federal 8.078/90, principiológica, de ordem pública e interesse social, se mostra corolário com o princípio constitucional da igualdade e da dignidade da pessoa humana expressos na Constituição Federal Brasileira, pois busca incansavelmente o equilíbrio da relação jurídica de consumo protegendo o consumidor, considerado vulnerável de forma socioeconômica, técnica ou jurídica, e garantindo a todos o acesso com qualidade e segurança aos produtos e serviços disponíveis no mercado de consumo, que acabam refletindo, positiva ou negativamente, na existência digna do ser humano em sociedade.

O respeito à dignidade da pessoa humana fica evidenciado, principalmente, pelo reconhecimento legal e presumido da vulnerabilidade do consumidor em relação ao fornecedor, exigindo um tratamento especial e diferenciado trazido ao consumidor pelo estatuto consumerista, que destaca nos seus princípios a vulnerabilidade do consumidor, parte mais “fraca" na relação jurídica de consumo, assim, também, observando o princípio constitucional 
da igualdade, onde a lei deve tratar desigualmente os desiguais na medida de suas desigualdades para então, garantir a igualdade real, concreta entre as partes.

A efetivação das normas de consumo no Brasil é essencial para o justo equilíbrio da relação jurídica de consumo, possibilitando o alcance da justiça no acesso e na distribuição dos bens materiais de consumo, principalmente dos produtos e serviços considerados essências, garantindo assim, o mínimo para a existência digna de cada ser humano em sociedade.

$\mathrm{Na}$ atualidade é clara a grande influência que o consumo impulsivo, inconsciente pode causar na sociedade. A necessidade de consumir para existir socialmente acaba marginalizando aqueles que não estão dentro dos padrões aceitos pela maioria como corretos ou normais, são eles, que não possuem nem uma boa condição financeira para arcar com suas dívidas essenciais, que são impulsionados por esse consumismo social e acabam na tomada injusta de créditos com juros e taxas absurdas, levando cada vez mais a uma condição ainda mais vulnerável e mais excluída.

Com a aplicação do princípio da conscientização do consumidor e com a efetivação do direito à educação para o consumo, por exemplo, é perfeitamente possível a diminuição de problemas como esse retratado acima, pois o consumidor consciente, conhecedor de seus direitos e deveres, não se "vende" facilmente as promessas de felicidade e satisfação garantida pelo consumo e nem se baseia na meramente nos valores materiais impostos pela sociedade de consumo.

De acordo com os dados divulgados pelo Instituto Brasileiro de Geografia e Estatística, em 2013, o consumo de produtos e serviços pelas famílias brasileiras representou, sob a ótica da demanda, mais de 60\% do Produto Interno Bruto (PIB) nacional (IBGE, on line, 2014), comprovando que mais da metade da economia do país depende direta ou indiretamente das relações jurídicas de consumo, o que torna evidente a necessidade da efetividade do direito fundamental do consumidor para que tenhamos uma relação jurídica justa e equilibrada, que possa realmente "sustentar" o desenvolvimento socioeconômico do nosso país.

É evidente que o desenvolvimento socioeconômico do Brasil é fator fundamental para a efetivação da inclusão social e dos princípios constitucionais da igualdade e da dignidade da pessoa humana, pois os países desenvolvidos demonstram notoriamente melhor qualidade de vida para seus cidadãos, garantindo o acesso a produtos e serviços públicos ou privados a todos de forma igualitária, necessários a concretização dos direitos humanos fundamentais e sociais.

O principal desafio da proteção e defesa do consumidor contemporâneo não é tão somente a distribuição correta das obrigações e dos direitos do fornecedor e do consumidor, mas sim a conscientização deste último, quanto à necessidade da aquisição de produtos e serviços, 
muitas vezes supérfluos, de forma exacerbada, desvirtuando a característica de direito humano e fundamental da proteção consumerista, por isso tamanha a importância desse instituo jurídico na proteção social.

Esperamos que com o reconhecimento da importância do direito do consumidor e da efetivação de sua proteção e defesa, como fator necessário à existência digna do ser humano em sociedade, ou seja, como direito fundamental essencial ao cumprimento do princípio da dignidade humana e a igualdade social, o objetivo da previsão constitucional da defesa do consumidor seja alcançado, trazendo equilíbrio às relações jurídicas de consumo, diminuindo e evitando graves problemas sociais vinculados ao consumo inconsciente e exacerbado.

Importante destacarmos que o endividamento causado pelo consumo desequilibrado e, muitas vezes até irracional, traz um grave reflexo negativo na vida social e pessoal do consumidor, o que reflete diretamente na sua dignidade. Com o inadimplemento de suas obrigações, o consumidor tem seu nome registrado ou "negativado" nos órgãos de proteção ao crédito, como por exemplo, o Serasa e o Serviço Central de Proteção ao Crédito (SCPC), os mais conhecidos popularmente.

A inclusão no rol de devedores causa, aos consumidores, problemas como a negativa de novos créditos para aquisição de bens essenciais à sua sobrevivência e a dificuldade de inclusão no mercado de trabalho, o que torna quase impossível negociar as dívidas e, consequentemente, honrá-las. Sendo assim, torna-se um círculo vicioso, em que o consumidor endividado não consegue renda para quitar suas dívidas e com estas tem seu nome negativado e não consegue emprego para ter renda.

Essa situação do consumidor superendividado, causa no mínimo, um sério desconforto ao cidadão que não consegue viver de forma digna em sociedade, abdicando de seu próprio sustento, do sustento de sua família e de suas necessidades básicas, o que na sociedade consumista em que vivemos, acaba sendo sinônimo de exclusão e marginalização social, fatoque decididamente não compactua com os princípios da igualdade e da dignidade da pessoa humana.

Por todo o exposto, podemos concluir que o direito do consumidor é essencial ao desenvolvimento econômico e social digno de qualquer ser humano, e os problemas causados pelos desacertos das relações de consumo trazem uma realidade social muito distante da concepção de justiça distributiva que seria necessária a uma sociedade ideal.

Com a devida aplicação do direito básico e fundamental da proteção e da defesa do consumidor com o objetivo de garantir o acesso aos bens de consumo necessários a existência digna do ser humano, esperamos a verdadeira efetivação das normas consumeristas, alcançando 
o equilíbrio nas relações de consumo, conscientizando as partes envolvidas, consumidor e fornecedor, das consequências de suas ações no mercado de consumo, consequências estas, que afetam suas vidas diretamente e acabam por refletir na sociedade em geral, principalmente nos grupos sociais menos favorecidos e marginalizados.

Desse modo, o Código de Defesa do Consumidor busca evitar graves problemas sociais causados pelo consumo exacerbado, compensando as desigualdades do mercado, ou seja, entre consumidores e fornecedores, regulamentando e equilibrando a relação jurídica de consumo, com o fim maior de garantir a igualdade e a dignidade da existência e vida humana, o que possibilita o acesso justo de todo e qualquer cidadão aos produtos e serviços disponíveis no mercado de consumo, principalmente àqueles considerados essências para o ser humano.

\section{REFERÊNCIAS}

ALMEIDA, João Batista de. A proteção jurídica do consumidor. 2. ed. São Paulo: Saraiva, 2000.

ANDRIGUI, Fátima Nancy. A tutela jurídica do consumidor e o respeito à dignidade da pessoa humana. In: MIRANDA, Jorge; MARQUES DA SILVA, Marco Antonio (coord.) Tratado Luso-Brasileiro da dignidade humana. São Paulo: Quartier Latin, 2008.

BANCO CENTRAL DO BRASIL. Relatório de Estabilidade Financeira. Março de 2014. Disponível em: http://www.bcb.gov.br/htms/estabilidade/2014_03/refC2P.pdf. Acesso em 25 nov. 2014.

BANCO CENTRAL DO BRASIL. Indicadores de Inadimplência. Disponível em: http://www.bcb.gov.br/?INDECO. Acesso em 25 nov. 2014.

BAUDRILLARD, Jean. A sociedade de consumo. Tradução Artur Morão. Lisboa/Portugal: Edições 70, 2007.

BAUMAN, Zygmunt. Vida para Consumo: a transformação das pessoas em mercadorias. Tradução Carlos Alberto Medeiros. Rio de Janeiro: Jorge Zahar Ed., 2008.

A ética é possível num mundo de consumidores? Tradução Alexandre Werneck.

Rio de Janeiro: Jorge Zahar Ed., 2011.

A sociedade individualizada: vidas contadas e histórias vividas. Tradução José Gradel. Rio de Janeiro: Jorge Zahar Ed., 2008. 
[et al]. Capitalismo parasitário: e outros temas contemporâneos. Tradução Eliana Aguiar. Rio de Janeiro: Jorge Zahar Ed., 2010.

Comunidade: a busca por segurança no mundo atual. Tradução Plínio Dentzien. Rio de Janeiro: Jorge Zahar Ed., 2003

Globalização: as consequências humanas. Tradução Marcus Penchel. Rio de Janeiro: Jorge Zahar Ed., 1999

BENJAmin, Antônio Herman V. Comentários ao Código de Proteção do Consumidor. Coord. de Juarez de Oliveira. São Paulo: Saraiva, 1991.

. [et al]. Manual de Direito do Consumidor. 3. ed. atual. e ampl. São Paulo: Editora Revista dos Tribunais, 2010.

O Direito do Consumidor. Disponível em: http://www.amprs.org.br/arquivos/revista_artigo/arquivo_1277313638.pdf. Acesso em $04 \mathrm{dez}$ 2014.

BETING, Joelmir. Análise do dia. Traduzindo o economês. Eu consumo; logo, existo. Disponível em: http://www.joelmirbeting.com.br/noticias.aspx? IDgNews=2\& IdNews=3265. Acesso em: 18 jul. 2014.

CASTEL, R. As metamorfoses da questão social. Uma crônica do salário. São Paulo: Vozes, 1998.

CDC - Código de Defesa do Consumidor. Lei 8.078 de 11 de setembro de 1990. Disponível em: http://www.planalto.gov.br/ccivil_03/leis/18078compilado.htm. Acesso em: 20 jul. 2015.

CONFEDERAÇÃO NACIONAL DO COMÉRCIO DE BENS, SERVIÇOS E TURISMO. Pesquisas. Perfil do Endividamento das Famílias Brasileiras em 2013. Disponível em: http://www.cnc.org.br/sites/default/files/arquivos/o_perfil_do_endividamento_das_familias_b rasileiras_em_2013.pdf. Acesso em: 26 jul. 2014.

COMPARATO, Fábio Konder. A Proteção do Consumidor; Importante Capítulo do Direito Econômico. Revista de Direito Mercantil, Industrial, Econômico e Financeiro, São Paulo, v.13, nº15/16, 1974.

FEDERAÇÃO do Comércio de Bens, Serviços e Turismo do Estado de São Paulo (Fecomercio). Radiografia do Endividamento das Famílias Brasileiras. Julho de 2013. Disponível em: http://www.fecomercio.com.br/CMS-Site//Files/Uploads\%5C5\%5C2014-02-

07\%5C12042.pdf. Acesso em: 01 ago. 2013.

FEDERAÇÃO do Comércio de Bens, Serviços e Turismo do Estado de São Paulo (Fecomercio). Radiografia do Endividamento das Famílias Brasileiras. Junho de 2014. http://www.fecomercioes.com.br/assetmanager/assets/Radiografia\%20do\%20Endividamento \%20das\%20Fam\%C3\%ADlias\%20-\%202014.pdf. Acesso em: 20 nov. 2014. 
FOLHA S. PAULO. Mercado. Investimento reage e é destaque do PIB em 2013. Disponível em: $\quad$ http://www1.folha.uol.com.br/mercado/2014/02/1418619-investimento-reage-e-edestaque-do-pib-em-2013.shtml. Acesso em 28 jul. 2014.

G1. Globo.com. Notícias. Economia. Seu dinheiro. Disponível em: http://g1.globo.com/economia/seu-dinheiro/noticia/2012/06/taxa-media-de-inadimplenciabate-recorde-historico-em-maio.html. Acesso em: 10 jul. 2014.

GRINOVER, Ada Pellegrini [et al]. Código Brasileiro de Defesa do Consumidor: comentado pelos autores do anteprojeto. 10. ed. rev., atualiz. e reform. Rio de Janeiro: Forense, 2011, vol. I. Direito Material (arts. $1^{\circ}$ a 80 e 105 a 108).

GROTTI, Dinorá Adelaide Musetti. Teoria dos serviços públicos e sua transformação. Direito administrativo econômico. São Paulo: Malheiros, 2000.

IBGE - Instituto Brasileiro de Geografia e Estatística. Pesquisas. Resultados de Pesquisas. Contas Nacionais. Indicadores. Disponível em: http://saladeimprensa.ibge.gov.br/noticias?view=noticia\&id=1\&idnoticia=2591\&busca=1\&t= 2013-pib-cresce-2-3-totaliza-r-4-84-trilhoes. Acesso em: 27 jul. 2014.

IBGE - Instituto Brasileiro de Geografia e Estatística. Sala de Imprensa. Notícias. Resultados de Pesquisas. Receita dos serviços. Disponível em: http://cod.ibge.gov.br/3AIBF. Acesso em: 25 nov. 2014.

KANT, Immanuel. Fundamentação da Metafísica dos Costumes e Outros Escritos. Tradução Leopoldo Holzbach. São Paulo: Martin Claret, 2004.

KELSEN, Hans, 1881-1973. O problema da justiça. Tradução de João Baptista Machado. 5. ed. São Paulo: Martins Fontes, 2011.

Teoria Pura do Direito. Tradução João Baptista Machado. 6. ed. São Paulo: Editora Martins Fontes, 1998.

LIPOVETSKY, Gilles. Os tempos hipermodernos. Tradução Mário Vilela. São Paulo: Editora Barcarolla, 2004.

O império do efêmero: a moda e seu destino nas sociedades modernas. Tradução Maria Lucia Machado. São Paulo: Companhia das Letras, 2009.

MARQUES, Claudia Lima [et al]. Comentários ao Código de Defesa do Consumidor. 3. ed. rev. atual. e ampl. São Paulo: Editora Revista dos Tribunais, 2010.

[et al]. Prevenção e tratamento do superendividamento. Brasil. Ministério da Justiça. Departamento de Proteção e Defesa do Consumidor. Brasília: DPDC/SDE, 2010.

Consumo como igualdade e inclusão social: a necessidade de uma lei especial para prevenir e tratar o "superendividamento" dos consumidores pessoas físicas. Revista Jurídica da Presidência/Presidência da República. Centro de Estudos Jurídicos da Presidência - Vol. 1, n. 1, maio. Quadrimestral. Brasília: Centro de Estudos Jurídicos da Presidência, 1999. 
[et al]. Repensando o direito do consumidor: balanço do código de defesa do consumidor e o necessário diálogo das fontes na perspectiva de consolidação normativa do direito do consumidor. Revista Jurídica do Centro de Pesquisa de Estudos da Subchefia para Assuntos Jurídicos da Casa Civil da Presidência da República - Vol. 10, n. 90. Ed. Esp., p.01-38, abr./maio. Brasília, 2008. Disponível em: http://www.planalto.gov.br/ccivil_03/revista/Rev_90/Artigos/PDF/ClaudiaLima_Rev90.pdf. Acesso em: 25 out. 2014.

NISHIYAMA, Adolfo Mamoru. A proteção constitucional do consumidor. 2 ed. rev. atual. e ampl. São Paulo: Atlas, 2010.

NUNES, Luis Antônio Rizzato. Curso de Direito do Consumidor: com exercícios. 8. ed. São Paulo: Saraiva, 2013.

PASQUALOTTO, Adalberto. Fundamentalidade e efetividade da defesa do consumidor. Revista Direitos Fundamentais e Justiça. Programa de pós-graduação, mestrado e doutorado em Direito da PUC/RS. nº. 9. Rio Grande do Sul: HS Editora, 2009.

RAWLS, John. Uma teoria da justiça. Tradução de Jussara Simões. 3. ed. São Paulo: Martins Martins Fontes, 2008.

ROCHA, Cármen Lúcia Antunes. O princípio da dignidade da pessoa humana e a exclusão social, texto mimeografado, em palestra proferida na XVII Conferência Nacional da Ordem dos Advogados do Brasil, Rio de Janeiro, 29-8-1999. Disponível em: http://www.egov.ufsc.br/portal/sites/default/files/anexos/32229-38415-1-PB.pdf. Acesso em: 19 jul. 2014.

SANDEL, Michael J. Justiça - O que é fazer a coisa certa. Tradução de Heloisa Matias e Maria Alice Máximo. 9. ed. Rio de Janeiro: Civilização Brasileira, 2012.

. O que o dinheiro não compra: os limites morais do mercado. Tradução de Clóvis Marques. Rio de Janeiro: Civilização Brasileira, 2012.

SARLET, Ingo Wolfgang. Direitos fundamentais sociais, mínimo existencial e direito privado. Revista de Direito do Consumidor. Vol. 61. 2007.

SCIRÉ, Cláudia. Aumento da renda não vem acompanhado do acesso aos direitos sociais. Disponível em: http://www.mobilizadores.org.br/coep/publico/consultarConteudo.aspx?TV. Acesso em: 15 jan. 2013.

SERASA Experian. Indicadores Econômicos. Inadimplência do Consumidor. Disponível em: http://www.serasaexperian.com.br/release/indicadores/inadimplencia_consumidor.htm.

Acesso em: 25 jun. 2014.

SILVA, Ana Beatriz Barbosa. Mentes consumistas: do consumismo à compulsão por compras. 1. ed. São Paulo: Globo, 2014. 
SILVA, José Afonso da. A dignidade da pessoa humana como valor supremo da democracia. Revista de Direito Administrativo, Rio de Janeiro, n. 212, abr/jun 1998.

SMITH, Jon. O mito da igualdade. Disponível em: http://inacreditavel.com.br/wp/o-mito-daigualdade/. Acesso em: 24 nov. 2014.

SPC, Brasil. Imprensa. Pesquisas. Disponível em: https://www.spcbrasil.org.br/imprensa/pesquisas. Acesso em: 05 mar. 2015. 